\title{
LA MODERNIZACIÓN DE LA SEGURIDAD SOCIAL EN SALUD Y LAS ENTIDADES PRESTADORAS DE SALUD (EPS)
}

\author{
CPC. Eduardo Alberto Montes Farro* \\ Dr. Luis Bortesi Longhi** \\ Mg. Esteban Avelino Sánchez*** \\ Mg. Vladimir Rodriguez Cairo****
}

\section{INTRODUCCIÓN}

La seguridad social en salud es de interës común; el bienestar propio y el ajeno contribuyen interactivamente al bienestar de todos. Es tan importante, que está en juego, incluso, la supervivencia de la especie humana. Es necesario que todos contribuyamos para que la salud prevalezca y posibilite en la vida personal y social el desarrollo $\mathrm{y}$ el bien vivir.

Las acciones que se hagan con este fin deben organizarse lo más eficientemente posible. El esfuerzo que hagamos todos facilitará la consecución del bienestar común.

Los estados buscan establecer los mejores mecanismos y acciones que normen conductas y procedimientos efectivos. Sin embargo, en la práctica no se logra.

El 17 de mayo de 1997 se promulgó la Ley $\mathrm{N}^{\circ}{ }^{\circ} 26790$, denominada Ley de Modernización de la Seguridad Social en Salud; y su Reglamento, el 9 de septiembre de 1997, mediante Decreto Supremo N. ${ }^{\circ}$ 009-97-SA.

La novedad de estos dispositivos legales consiste en un intento de privatizar, en parte inicialmente, el servicio de atención mediante: Entidades Prestadoras de SaludEPS.

Para supervisar las EPS, se crea la Superintendencia de Entidades Prestadoras de Salud-(SEPS); que el 3 de agosto de 1999 aprueba el Plan de Cuentas con el objeto de vigilar la solidez económica y patrimonial de las EPS y de recabar información oportuna y sistemática.

Es el preciso comprender la diferencia del Sistema de Seguridad Social y Régimen de Seguro Social; en este último caso no se contempla la cobertura general, como lo menciona la Constitución del Estado en el artículo $10^{\circ}$ : el derecho universal de toda persona a la seguridad social.

* Docente Asociado y Coordinador del Departamento Acadēmico de la Facultad de Ciencias Contables

* Docente Auxiliar de la Facultad de Ciencias Contables

*** Docente Auxiliar de la Facultad de Ciencias Contables

**** Docente Auxiliar de la Facultad de Ciencias Contables 
También hay que tener presente que por principio la Seguridad Social no se restringe al ámbito curativo sino sobretodo al preventivo y a los aspectos económicos, sociales y culturales, que coadyuven al logro de la salud.

\section{Entorno Económico y Social del Perú}

La Política del gobierno podría esquematizarse de la siguiente manera:

\section{Sector Financiero}

- Política Tributaria, Fiscal y Monetaria

- Emisión de Deuda Soberana (Interna y Externa)
Sector Económico Productivo. Subdividido en:

- Primario. Agricultura, Ganadería, Forestal, Minería y Pesca

- Secundario. Industria, Transporte, Comunicaciones, Comercio, Exportaciones y Turismo.

\section{Sector Social}

- Política en Educación, Salud, Vivienda y de Trabajo y Promoción de Empleo.

Todos los sectores interactúan y de alguna manera afecta favorable o desfavorablemente en la salud.

\section{Población Estimada:}

Segủn ubicación

\begin{tabular}{c|r|r|r|r|r|r|}
\cline { 2 - 7 } & \multicolumn{2}{c|}{2,002} & \multicolumn{2}{c|}{2,003} & \multicolumn{2}{c|}{2.004} \\
\cline { 2 - 7 } & $26,748,972$ & $100.00 \%$ & $27,148,101$ & $100.00 \%$ & $27,546,574$ & $100.00 \%$ \\
\hline Urbana & $19,310,309$ & $72.19 \%$ & $19,638,160$ & $72.34 \%$ & $19,966,180$ & $72.48 \%$ \\
\cline { 2 - 7 } & $7,438,663$ & $27.81 \%$ & $7,509,941$ & $27.66 \%$ & $7,580,394$ & $27.52 \%$ \\
\hline
\end{tabular}

Se puede apreciar que cada vez más población se concentra en las ciudades

Asalariados, Subempleados y Desempleados en Lima (En miles)

\begin{tabular}{|c|c|c|c|c|c|c|}
\hline Años & PEA & Asalariados & Subempleados & Desempleados & TDC & NTC \\
\hline 1991 & 2.405 & 1,286 & 977 & 142 & $5.90 \%$ & $11.04 \%$ \\
\hline 2001 & 3,742 & 1,680 & 1,731 & 331 & $8.85 \%$ & $19.70 \%$ \\
\hline
\end{tabular}

$\mathrm{Si}$ revisamos la Tasa de Desempleo Convencional (TDC), del año 2001:

Desempleados / PEA $=331 /$ $3742=\mathbf{8 . 8} \%$,
Resultaría comparable con Estados Unidos y Europa

Pero si utilizamos la Nueva Tasa de Desempleo (NTC), del mismo año 2001, obtendriamos: 
Desempleados / Asalariados = $331 / 1680=19.7 \%$,

Se puede distinguir con mayor objetividad la realidad.

Con la promulgación de la Ley N. ${ }^{\circ} 26790$, llamada "De Modernización de la Seguridad Social en Salud" en buena cuenta se establecen las pautas de un Régimen de Seguro Social, mas que un Sistema de Seguridad Social.

\section{Seguridad Social en Salud}

Se intenta orientar hacia la unificación y universalización de la cobertura de salud de la población.

Para tal fin plantea un nuevo sistema de cobertura para toda la población, conformado por un Régimen Contributivo constituido por el Seguro Social de Salud, a cargo de Essalud y complementado por las Entidades Prestadoras de Salud-EPS; y el Régimen Estatal, No Contributivo, a cargo del Ministerio de Salud.

Entidades empleadoras.Empresas o instituciones públicas o privadas que emplean trabajadores dependientes.

El Régimen Contributivo es obligatorio y da cobertura a:

- Trabajadores activos dependientes. Que laboran bajo relación de dependencia o en calidad de socios de cooperativas de trabajadores.

- Pensionistas. Perciben pensión de cesantía, jubilación, incapacidad o sobrevivencia.

- Derechohabientes. Cónyuge o concubino, hijos menores de edad o mayores incapacitados.
También contempla a:

- Potestativos. Trabajadores y profesionales independientes y demás personas que no califiquen para la afiliación regular y todos aquellos que determine la ley, como: escolares, trabajadoras del hogar, etc.

\section{Situación antes de la Ley $N .^{\bullet} 26790$}

El Seguro Social de Salud (Essalud) cubre aproximadamente $25 \%$ de la población nacional.

\section{Población del Perú} 24'793,880 habitantes

Titulares a Nivel Nacional 2'662,307

Dependientes o Derechohabientes 3'650,000

Total Población Cubierta por ESSALUD $6,312,000$

También debemos notar que:

Los titulares en Lima son 1`307,668 habitantes que representa el $50 \%$ de los titulares de todo el país.

\section{PLANTEAMIENTO DE LA LEY N. 26790}

Dar un primer paso en la reforma del sector salud propiciada por el Gobierno, planteando la participación privada:

Atención de servicios:

Capa simple: Essalud EPS (Entidades Prestadoras de Salud) 
Capa compleja: Essalud

EPS (Plan

Complementario)

Opcional

Capa simple. Conjunto de intervenciones de Salud de mayor frecuencia y menor complejidad.

Capa compleja: Conjunto de intervenciones de salud de menor frecuencia y mayor complejidad, Ejemplo: Intervenciones quirürgicas de alto riesgo. Está a cargo de Essalud, permitiendo que las EPS vayan asumiendo mayor cobertura a medida que se fortalezcan.

\section{APORTES}

Entidades empleadoras: Pagan el 9\% de las remuneraciones

\section{Correspondiendo si:}

Afiliado a Essalud: 9\% de las remuneraciones

Afiliado a una EPS:

$\begin{array}{ll}\text { Essalud } & 6.75 \% \text { de las } \\ & \text { remuneraciones } \\ \text { EPS } & 2.25 \% \text { de las } \\ & \text { remuneraciones }\end{array}$

Los afiliados a una EPS no pierden su derecho a ser atendidos por Essalud, especialmente la capa compleja.

Las entidades prestadoras de salud-(EPS) brindan coberturas de salud a través de sus planes de salud. Los planes deben otorgar como mínimo la capa simple, pudiendo otorgar mayores coberturas, como hemos visto.

\section{Afiliación de los trabajadores a las} EPS

Los empleadores, en acuerdo con los trabajadores, eligen un plan de salud; y debe pagarse una prima mensual a una EPS.

La contribución del $2.25 \%$ de las remuneraciones forman parte de la prima.

Pueden convenirse copagos, a cargo del asegurado, "destinados a promover el uso equitativo de las prestaciones"

El copago es un pago adicional a la prima, en el momento de la atención.

En opinión de algunos Consultores de Negocios:

Un peruano gasta en Salud un Promedio de 100 dólares anuales, cifra considerada muy baja en comparación con otros paises de la tégión. Sin embargo, este gasto no es uniforme, ya que según la estructura económica, alrededor de cinco millones de peruanos no tienen acceso a servicios de salud.

También sostienen los mencionados consultores:

El Sector Privado debe apuntar a grupos de menores ingresos; porque hay buenas perspectivas para el Sector Privado de Salud si es capaz de dar precios que puedan pagar.

\section{La Superintendencia de las Entidades Prestadoras de Salud- SEPS}

El artículo N. ${ }^{\circ} 14$ de la Ley N. ${ }^{\circ}$ 26790 crea la Superintendencia de las Entidades Prestadora De SaludSEPS, con el objeto de autorizar, regular $y$ supervisar el funcionamiento de las entidades 
prestadoras de salud y Cautelar el Uso de los fondos por estas administradoras.

\section{Recaudación de los Aportes y Primas \\ Los empleadores informan al detalle las contribuciones correspondientes por los ingresos de los trabajadores, mediante el PDT, ante la SUNAT.}

También se informa si sus trabajadores tienen contrato con algunas EPS; deduciendo el $25 \%$ de la Contribución, que servirá, como parte de la prima a la EPS.

\section{Dificultades en la Práctica}

Essalud. Todos sabemos de la intervención de los gobiernos para usar sus fondos e incrementar la burocracia y la ineficiencia.

SUNAT es informada al detalle de los aportes de los contribuyentes que cumplen; pero Essalud no lleva un control eficiente que permita el seguimiento de sus cuentas por cobrar.

Adicionalmente, muchas instituciones estatales no cumplen con entregar los aportes, creando problemas financieros

EPS. Las EPS gestionan principalmente los servicios de Salud a través de terceros: Clínicas, médicos y otros centros de salud. Llevar el control de las atenciones, cobros y pagos es muy complejo.

Todo esto encarece los servicios y genera retrasos en la atención a los asegurados y de los pagos.

\section{Sistema de Información Integrado de la Seguridad Social en Salud}

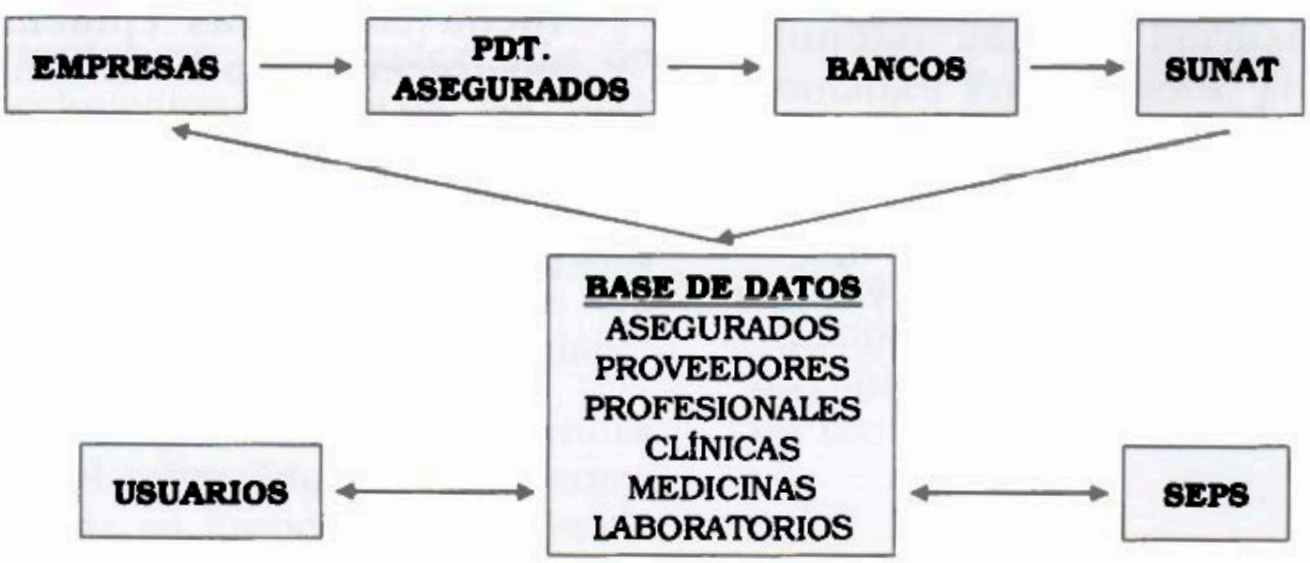

Como se puede apreciar el Sistema de Información en una EPS, como en Essalud, es bastante complejo.

Veamos 2 ejemplos: 1) cuando la empresa contrata los servicios de prestación de salud, sobre la base de lo requerido, se tiene que calcular la prima correspondiente según el número de asegurados y el tipo de servicios; y registrar detalladamente a cada beneficiario.

También debe facturar periódicamente, para cubrír las primas y cobrar los adicionales que hayan surgido. 
2) El segundo ejemplo es que se debe llevar un control minucioso de cada expediente de usuario y la historia de su atención; así como saber los médicos o que centro de salud tienen actualmente atención de asegurados y si la atención es satisfactoria.

\section{CONCLUSIONES}

Las autoridades, dentro de las limitaciones existentes, dan prioridad a la atención médica a los enfermos; desatendiendo las causas que deterioran la salud de la población.

La contaminación ambiental de todo tipo no es enfrentada con la decisión necesaria.

Falta educación sobre alimentación y salubridad y determinar las causas de la desocupación y el riesgo a los accidentes. Es decir, existe una pobreza económica y cultural.

\section{RECOMENDACIONES}

- Tomar conciencia de la magnitud del problema y resolver las causas de la falta de salud (física, moral y cultural).

- Promover la información y desarrollar la eficiencia en todas las actividades. Los profesionales deben desarrollar mejores sistemas de información para apoyar la gestión eficiente de todas las actividades relacionadas con la seguridad social.

- Tener presente que saber cuidarse es una necesidad tanto individual como colectiva. Es individual, pues cada persona es responsable de su cuerpo: envejecer con buena salud consiste ante todo en respetar las necesidades del organismo, practicando buenos hábitos de vida, evitando las cosas nocivas (tabaco y alcohol), interpretando las señales de alarma (fiebre, dolor, etc.) que el cuerpo nos envía. Es una necesidad colectiva, por cuanto se trata de lucha contra las epidemias, favorecer la prevención de enfermedades (como el sida), proteger a las personas de ciertos peligros (por ejemplo, los accidentes de tránsito). 